\title{
Fixed-ratio responding with human subjects*
}

R. FRANK WALLACE

University of California, San Diego, La Jolla, Calif. 92037

\author{
and \\ DAVID W. MULDER \\ University of Utah, Salt Lake City, Utah 84112
}

Retarded adult humans were observed when allowed to press a button for candy on various fixed-ratio schedules of reinforcement. The results demonstrated that the size of the required fixed ratio was directly related to the length of the postreinforcement pause. However, fixed-ratio size had no effect on response rate when responding resumed following the postreinforcement pause.

In fixed-ratio (FR) schedules, the reinforcing stimulus is presented for every nth response. The resulting pattern of behavior is a period of nonresponding followed by rapid responding until the completion of the ratio. In studies using infrahuman Ss, the period of nonresponding, or the postreinforcement pause (PRP), has been shown to increase in length as the size of the FR requirement is increased (Felton \& Lyon, 1966; Powell, 1968).

The occurrence of postreinforcement pausing has been reported when the Ss used were normal children (Long, Hammack, May, \& Campbell, 1958; Long, 1959; Weisberg \& Fink, 1966), retarded children (Orlando \& Bijou, 1960; Bijou \& Orlando, 1961), normal adults (Holland, 1958), and retarded adults (Ellis, Barnett, \& Pryer, 1960).

While Long et al (1958) report less pausing when the FR size is decreased, others have reported the absence of increased pausing with humans at higher FR values (Hutchinson \& Azrin, 1961; Holland, 1958; Ellis et al, 1960). Because of this intra- and interspecies inconsistency, it was decided to replicate with humans the previous infrahuman study by Powell (1968), in which FR size was parametrically varied and the affect on postreinforcement pausing was observed.

\section{METHOD \\ Subjects}

Three severely retarded adults (IQs less than 30; ages 28, 31, and 36 years) served as Ss for this study. All three individuals were institutionalized and had previously worked in a sheltered workshop.

\section{Apparatus}

Sessions were run in an isolated room that was approximately $6 \times 8 \mathrm{ft}(1.8 \times 2.4 \mathrm{~m})$ in size. The Ss were seated in front of a

\footnotetext{
*The authors would like to thank Steven Spiro for his aid in collecting the data and Dr. E. J. Fantino for his editorial comments and sponsorship of the paper. Reprints may be obtained from R.F. Wallace, Department of Psychology, University of California, San Diego, P.O. Box 109, La Jolla, California 92037.
}

wooden panel which contained a pushbutton $(2.54 \mathrm{~cm}$ in diam and requiring approximately $300 \mathrm{~g}$ force for depression), two 7-W pilot lights, and a small plastic tray. Located behind the panel was a candy dispenser used to present the reinforcers, small sugar-coated candies. Standard electromechanical control and recording apparatus was located in an adjacent room.

\section{Procedure}

The Ss were brought individually to the experimental room and asked if they would like to earn some candy. When they answered affirmatively, they were shown how to depress the button in order to operate the candy dispenser. Once they had made a few responses, which were reinforced on an FR 1, they were given a small paper bag and told they could earn more candy and take it back to their rooms with them. At that point, they were left alone in the room to earn more candy on the FR 1. This and all other sessions were terminated when the $S$ had acquired 50 reinforcers. In following sessions the ratio requirement was slowly raised to an FR 20 and held at that level until the behavior met the Schoenfeld, Cumming, \& Hearst (1956) stabilization criterion at 5\%. For two of the Ss, the FR values used were $20,30,40,60,80,120$, and 160 . For the third $S$, the values used also included FR $240,320,480$, and 640 . The values were all presented in ascending order and selected values were presented in descending order. In addition, when the initial results were inconsistent, some values were re-presented for further evaluation.

The PRP was measured from the delivery of the reinforcing stimulus to the next response. Response rate was calculated by dividing the number of responses by the time from the first response after reinforcement (end of PRP) to the completion of the FR requirement.

\section{RESULTS}

The first S, J.G., increased his PRP length as the FR requirement was increased (Fig. 1). As can be seen, the average pause length for the descending series FRs was less than the values for corresponding ascending series FRs. A separation of PRPs into eight 5-sec frequency bins showed that the effect of increasing the response requirement was to increase the mode and variability of the pause lengths. Thus, the increase in mean pause length was not due to the occurrence of a few long pauses but to an overall change in the pausing behavior.

As the FR requirement was raised from FR 20 to FR 30, the response rate increased but remained roughly constant thereafter, demonstrating no effect of the ratio requirement on rate of response (Fig. 2).

The second S, J.M., decreased his PRPs as the ratio requirement was raised through FR 20, 30, 40, and 60 (Fig. 1). At values above FR 60, the pause lengthened with increases in the FR requirement. Redetermination of some of the lower ascending FR values yielded a positive relationship between pause length and the FR requirement. This $S$ showed the same tendency to pause for a shorter time on ascending FR values than on corresponding ascending values. The same increases in the mode and variability of pause length were noted as with the previous $S$.

Response rates for J.M. increased across all the initial 


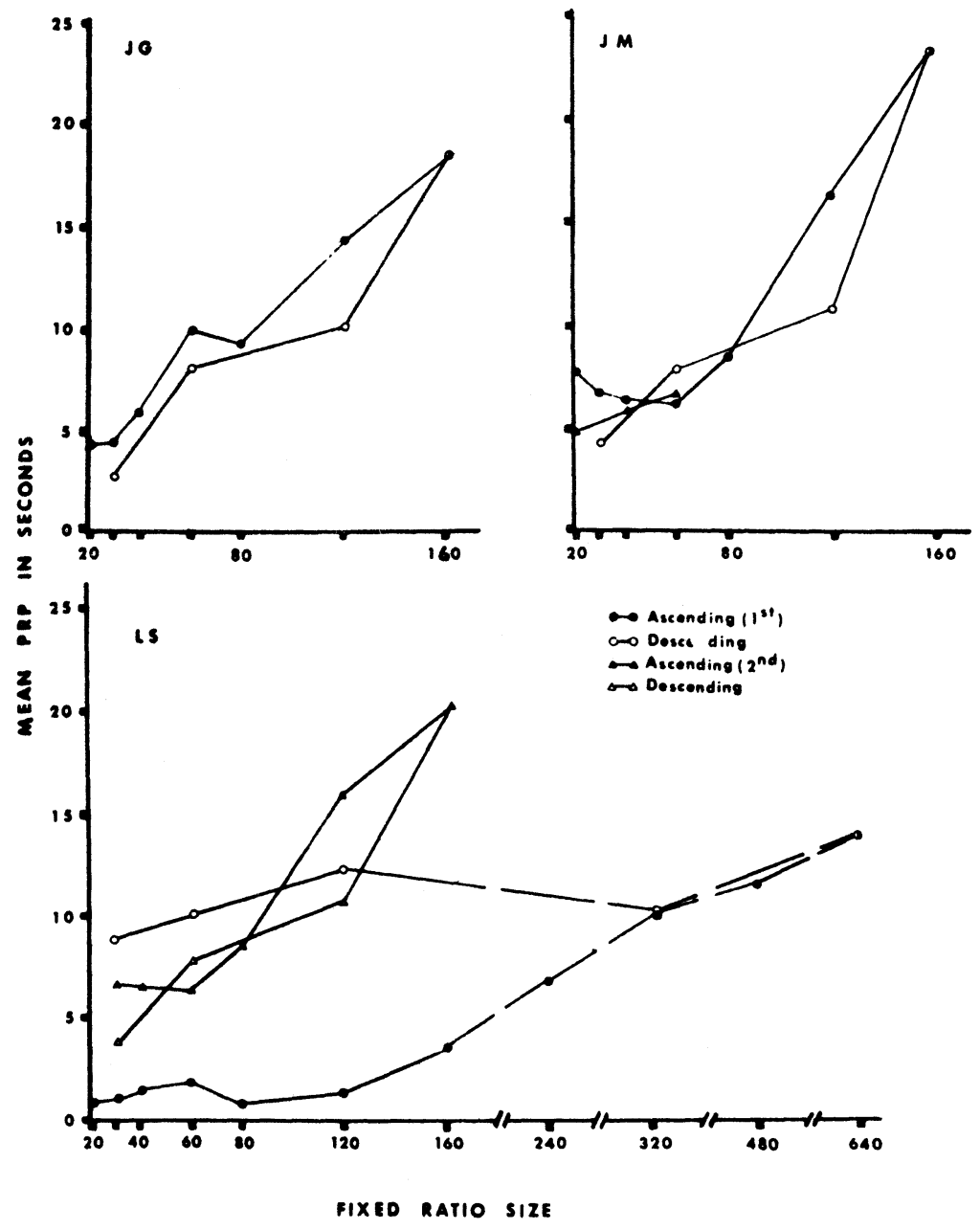

Fig. 1. Mean postreinforcement pause length as a function of fixed-ratio requirement, both ascending and descending series presentations.

FR values, both ascending and descending (Fig. 2). At the final descending FR value, a ceiling rate of responding was reached and maintained throughout the redetermination of the first three values. Direct observation of the $S$ revealed a change in his response topography during the study. Initially he would sit in a chair in front of the console and push the button with one hand, removing his hand from the vicinity of the button after each response. By the final descending FR value, he was standing in front of the console and rapidly operating the button with both hands, using an almost vibrating motion. Once this more efficient response topography had evolved, ratio size did not affect response rate.

The third S, L.S., showed little effect from increasing the ratio requirement through FR $20,30,40,60,80$, and 120, pausing less at FR 80 than at FR 20. When the requirement was raised to FR 160 , the PRP increased noticeably and continued to increase with successive increases in the FR requirement (Fig. 1). The descending series showed some irregularity, with the FR-320 PRP being less than the FR-120 pause. Re-presentation of several of the FRs showed an increase in the pause length starting at FR 80, with descending values generally less than corresponding ascending values. Again the changes in pause length were due to a shift in the mode and variability. The response rate for this $S$ (as with the previous two Ss, barring the noted exception with J.M.) was unaffected by the ratio requirement (Fig. 2).

\section{DISCUSSION}

For all three Ss, there was a fairly orderly relationship between the FR requirement and the size of the PRP. One $S$, L.S., initially showed a degree of insensitivity to low FRs, not starting to increase his pause length until the requirement had been raised to FR 160 . Similar results have been observed in pigeons when the FR value was increased gradually over a long period of time. ${ }^{1}$ For the pigeons, as with L.S., once pausing appeared on FR schedules, it continued for both higher and lower FR values.

Another S, J.M., did not initially demonstrate increased pause time as the FR requirement was increased. This can perhaps be explained by the accompanying change in his response topography and resulting response rate increase. Killeen (1969) has demonstrated that the length of the postreinforcement pause is determined by the interreinforcement time and not by the number of responses which occur during the interval. For J.M. the increasing response rate during the early part of the study might have served to offset the increased number of responses required, thus minimizing the change in interreinforcement time. 


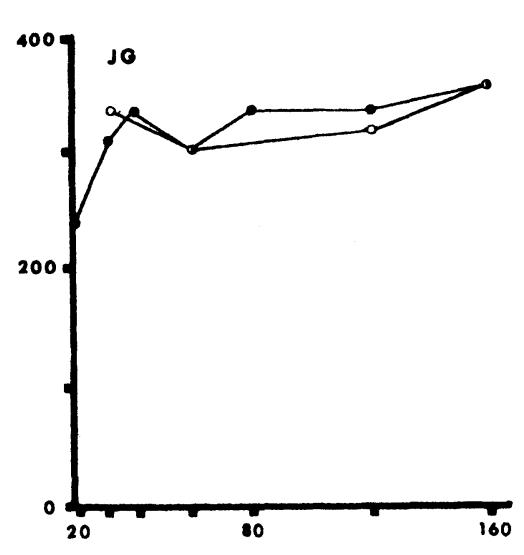

ב a function of fixed-ratio requirement.
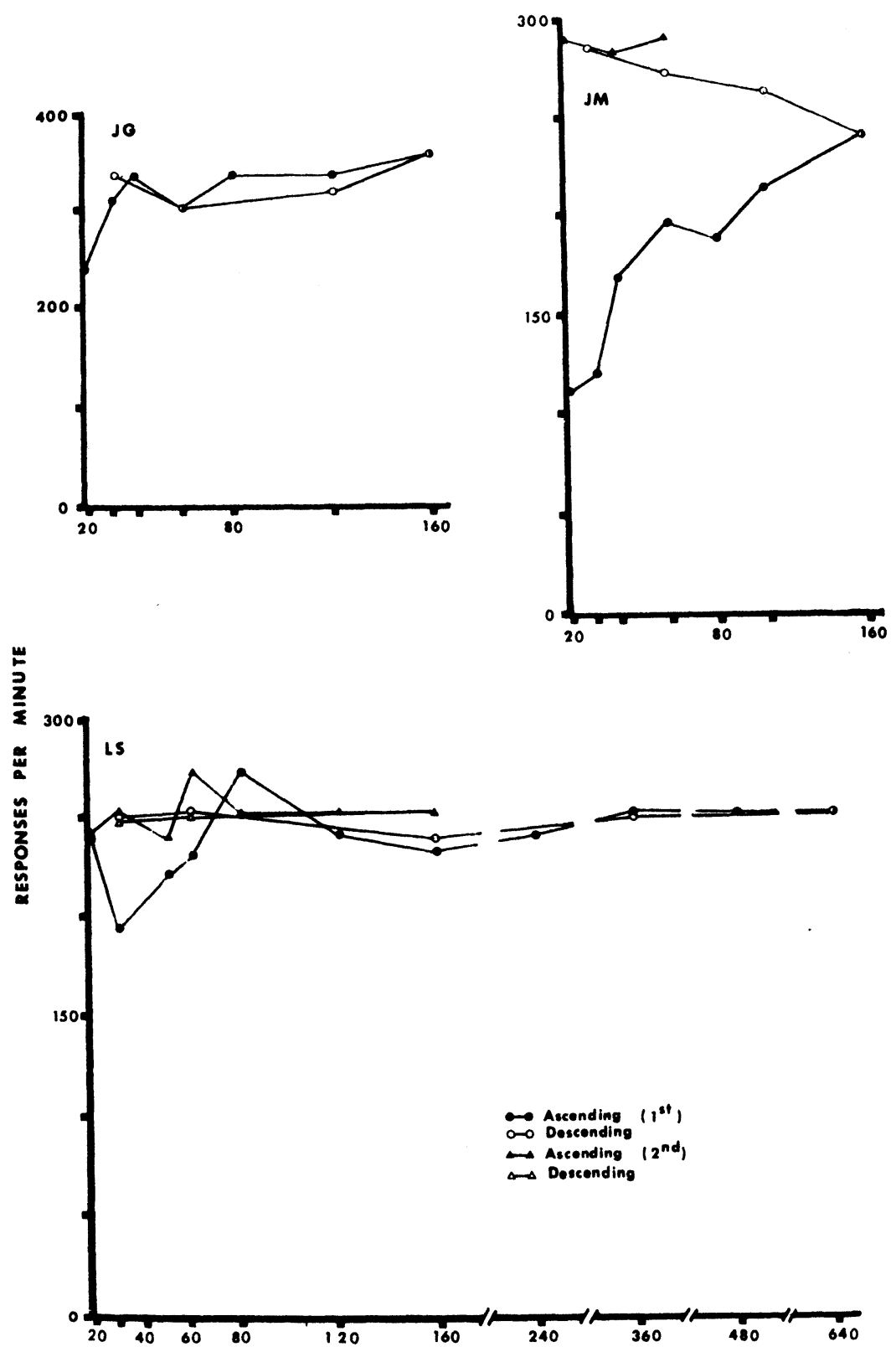

FIXED RATIO SIZE

This, in conjunction with the more convenient physical location of the $S$, could account for the apparent initial inconsistency between FR size and PRP length.

The inconsistency in demonstrating the FR-PRP relationship between studies using human Ss can perhaps be attributed to two methodological differences. When failures to obtain increased PRP lengths with FR increases have occurred, there has been no required consummatory response that was incompatible with responding (Holland, 1958; Hutchinson \& Azrin, 1961). Other studies where failures have occurred have given Ss instructions to work as rapidly as possible (Holland, 1958) or have exposed the Ss to FR schedules for only short periods of time (Ellis et al, 1960), thus possibly confounding the schedule effects with their particular experimental design. Therefore, it appears that, when humans are tested on FR schedules in situations similar to those used with animals (free of procedural constraints), the relationship between FR value and PRP length occurs.

\section{REFERENCES}

Bijou, S. W., \& Orlando, R. Rapid development of multiple schedule performances with retarded children. Journal of the Experimental Analysis of Behavior, 1961, 4, 7-16.

Ellis, N. R., Barnett, C. D., \& Pryer, M. W. Operant behavior in mental defectives: Exploratory studies. Journal of the Experimental Analysis of Behavior, 1960, 3, 63-69.

Felton, M., \& Lyon, D. The post-reinforcement pause. Journal of the Experimental Analysis of Behavior, 1966, 9, 131-134.

Holland, J. G. Counting by humans on a fixed-ratio schedule of reinforcement. Journal of the Experimental Analysis of Behavior, 1958, 1, 179-181.

Hutchinson, R. R., \& Azrin, N. H. Conditioning of mental hospital patients to fixed-ratio schedules of reinforcement. Journal of the Experimental Analysis of Behavior, 1961, 4, 87-95. 
Killeen, P. Reinforcement frequency and contingency as factors in fixed-ratio behavior. Journal of the Experimental Analysis of Behavior, 1969,12, 391-395.

Long, E. R. Multiple scheduling in children. Journal of the Experimental Analysis of Behavior, 1959, 2, 268.

Long, E. R., Hammack, J. T., May, F., \& Campbell, B. J. Intermittent reinforcement of operant behavior in children. Journal of the Experimental Analysis of Behavior, 1958, 1, 315-339.

Orlando, R., \& Bijou, S. W. Single and multiple schedules of reinforcement in developmentally retarded children. Journal of the Experimental Analysis of Behavior, 1960, 3, 339-348.

Powell, $R$. W. The effect of small sequential changes in fixed-ratio size upon the post-reinforcement pause. Journal of the Experimental Analysis of Behavior, 1968, 11, 589-593.
Schoenfeld, W. N., Cumming, W. W., \& Hearst, E. On the classification of reinforcement schedules. Proceedings of the National Academy of Science, $1956,42,563-570$. Cited by $M$. Sidman, Tactics of scientific research. New York: Basic Books, 1960. P. 260

Weisberg, P.. \& Fink, E. Fixed-ratio and extinction performance of infants in the second year of life. Journal of the Experimental Analysis of Behavior, 1966, 9, 105-109.

\section{NOTE}

1. D. L. Myers, personal communication, 1972 .

(Received for publication March 8, 1973.) 